\title{
Projected changes of inundation of cyclonic storms in the Ganges-Brahmaputra-Meghna delta of Bangladesh due to SLR by 2100
}

\author{
Shazzadur Rahman ${ }^{1}$, A K M Saiful Islam ${ }^{1, *} \mathbb{D}$, Probal Saha ${ }^{1}$, \\ Abdur Rahman Tazkia ${ }^{1}$, Yann $\mathrm{Krien}^{2}$, Fabien Durand $^{3}$, Laurent Testut ${ }^{3}$, \\ G M TARekul Islam ${ }^{1}$ and Sujit Kumar Bala ${ }^{1}$ \\ ${ }^{1}$ Institute of Water and Flood Management (IWFM), Bangladesh University of Engineering and Technology \\ (BUET), Dhaka 1000, Bangladesh. \\ ${ }^{2}$ LARGE, University of the French West Indies, Guadeloupe, France. \\ ${ }^{3}$ Laboratoire d'Etudes en Géophysique et Océanographie Spatiales (LEGOS), Université de Toulouse, CNES, \\ CNRS, IRD, UPS, Toulouse, France. \\ ${ }^{*}$ Corresponding author. e-mail: akmsaifulislam@iwfm.buet.ac.bd
}

MS received 1 May 2018; revised 31 January 2019; accepted 15 March 2019; published online 31 May 2019

Almost every year, Bangladesh experiences disasters such as tropical cyclones, storm surges, coastal erosion or floods. Tropical cyclones originate from the North Indian Ocean and often cause devastating flood inundations in Bangladesh. Storm surges of the Bay of Bengal (BOB) are larger compared to other regions of the world for similar cyclones due to amplification by the shallow water depth, huge continental shelf and convergent coastlines. This scenario of inundation for such storm surges in the future when the sea level rise (SLR) occurs due to global warming will be different from the present. The densely populated coastal region of Bangladesh is likely to become more vulnerable in the future due to SLR. Disaster risks can be reduced if storm surges can be predicted well ahead. To assess the possible changes of inundation in the future, a widely used coastal model, Delft3D, has been applied for this BOB region. The model has been validated for the storm surge of three recent devastating cyclones, namely, Sidr, Aila and Roanu in the southern coast of Bangladesh. The validated model has been run to produce inundation maps and statistics for cyclonic storm surges such as Sidr, Aila and Roanu and probable SLR. Three possible SLR boundary conditions are chosen from the business-as-usual climate scenario representative concentration pathway 8.5 with values of $0.5 \mathrm{~m}$ (lower limit), $1 \mathrm{~m}$ (upper limit) and $1.5 \mathrm{~m}$ (extreme case, considering the subsidence and a rapid collapse of the Antarctic ice sheet). It is found that a category 4 cyclone such as cyclone Sidr would inundate $2.6 \%, 3.67 \%$ and $5.84 \%$ of the area of the country if the SLR is $0.5,1$ and $1.5 \mathrm{~m}$, which will affect the livelihood of nearly $4.1,7.0$ and 9.1 million people of Bangladesh, respectively. It will also inundate up to $21.0 \%, 42.1 \%$ and $65.1 \%$ of the Sundarbans mangrove forest, which will undoubtedly affect the ecology of this unique ecosystem.

Keywords. Bay of Bengal; climate change; cyclone; Delft3D; sea level rise; storm surge.

\section{Introduction}

Bangladesh is a south Asian country which experiences a plethora of natural disasters almost every year. Tropical cyclones, storm surges, floods, river bank erosion or landslides occur regularly. Tropical cyclones are the most common and devastating extreme weather events in Bangladesh. Almost 
every year, a cyclone originates from the North Indian Ocean (i.e., the Bay of Bengal (BOB) and the Arabian Sea). The BOB cyclones typically cross Bangladesh and adjoining West Bengal coast of India, and move in the north or the north-easterly direction (Shrestha et al. 1998). Bangladesh is also prone to severe flooding because of its geology, combined with river water from the melting Himalayan glaciers in the north and the encroaching BOB in the south (Dastagir 2015). This situation is aggravated by the occurrence of cyclones and subsequent storm surges. Some recent cyclones such as Sidr, Aila and Roanu followed by the heavy flood caused a large extent of destruction of life and property. Cyclone Sidr, a category 4 cyclone, made a landfall in Bangladesh on 15 November 2007. The maximum wind speed of the cyclone was $260 \mathrm{~km} / \mathrm{h}$ according to the Joint Typhoon Warning Center (JTWC). At least 3447 people were killed and crop fields were damaged with wind and a surge up to a height of $3 \mathrm{~m}$. Sidr was followed by two heavier-than-normal floods that killed some 1500 people and damaged about 2 million tons of food. Storm surges are severe, especially, in Bangladesh, because of the shape and characteristics of the coastline. The eastern parts of the coastline of Bangladesh can be considered as a wide continental shelf. Due to this characteristic, the storm surges amplify when propagating from the deep water to the seawater (Alam and Jabed 2015). The tangential wind of the tropical cyclone pushes the seawater from the south upwards to generate the storm surge. Moreover, cyclones and storm surges cause massive loss of life and properties as the coastal areas of Bangladesh are densely populated. Hence, the prediction of a storm surge would greatly help in reducing the impact of cyclones.

Considering the negative impact of climate change, Bangladesh has been considered as one of the most vulnerable countries. The global warming due to the increase in greenhouse gases concentrations in the earth's atmosphere and the consequent sea level rise (SLR) is going to add fuel to the fire. Almost every socioeconomic sector in Bangladesh is likely to be affected by climate change (Ramamasy and Baas 2007). Bangladesh ranked fifth in the Global Climate Risk Index, a ranking of 170 countries most vulnerable to climate change (Kreft and Eckstein 2013).

The mean sea level (MSL) is calculated as the average of hourly tide records measured by mechanical tide gauges over extended periods of time. Based on the context of the measurement, SLR can be termed as global SLR and relative SLR (Williams et al. 2009). According to the IPCC (2013), the relative sea level (RSL) is calculated on the basis of the earth land surface and the global sea level (GSL) is estimated based on the reference ellipsoid. On the other hand, the MSL is estimated for a given location for a long time average data. The spatial average of all MSL is defined as the global mean sea level (GMSL). The notion that sea level is changing was recognised in the first assessment report (AR) of the Intergovernmental Panel on Climate Change (IPCC), where the change from the year 1990-2001 was addressed (Warrick and Oerlemans 1990). Two major causes of SLR were identified (Church and White 2011). The first one is the expansion of ocean water due to global warming induced thermal expansion and the second one is the addition of ice water in the ocean from the land through the melting of glacier ice sheets (Church and White 2011). The first IPCC report also expressed that the SLR rate will be higher in the 21st century than in the 20th century and will continue to rise even if a significant reduction in the greenhouse gas (GHG) emissions is achieved. The processes that contribute to global and regional sea level changes encompass the ocean, atmosphere, land ice and the hydrological cycle. Thermal expansion and cryospheric contribution are the two main factors that are critical to SLR.

Bangladesh is vulnerable to current coastal hazards and anticipated SLR because of its low elevation. Drainage congestion and waterlogging are already an alarming problem in the coastal area of Bangladesh and are likely to be exacerbated by SLR and increased river flooding. Large uncertainties are associated with regional- to district-level estimates of inundation, which is due to the compounding effects of the variable rates of uplift and sedimentation, river flooding and erosion. Siltation is gradually increasing due to SLR. As a result of the reduced upstream flow, the silt flocculate/deposit in the riverbed which restricts the removal of excess water from the countryside and causes drainage congestion. The Northern Indian Ocean, which includes the BOB, has also been reported to experience a relatively high rate of SLR compared to other oceans globally (Unnikrishnan and Shankar 2007; Han et al. 2010). SMRC (2003) estimated the rise of sea level in Hiron Point, Char Changa and Cox's Bazar to be 4, 6 and $7.8 \mathrm{~mm} / \mathrm{yr}$, respectively. Ericson et al. (2006) predicted that the SLR of the BOB follows the trend of $10 \mathrm{~mm} / \mathrm{yr}$. 
The rising trend of the tides is almost twice on the eastern coast than that of the western coast. This difference could be due to the differential subsidence and uplifting of land.

Evidence for global mean SLR has been documented in all ARs of the IPCC. The IPCC continuously revises its projections of global mean SLR, drawing on the knowledge and data of the international scientific community. The projections of global mean SLR and its contributions have been generated for four representative concentration pathways (RCPs) and special report on emission scenarios (SRESs). The RCP is described as the emission and concentration of greenhouse gases, aerosols and chemically active elements from the present to the end of the century (Moss et al. 2008). Each RCP is the representative value out of many possible scenarios that would lead to specific radiative forcing characteristics. Here, pathway has been used to emphasise both the concentration and the trajectory that will be followed to reach it (Moss et al. 2010). The SLR estimations by IPCC include global as well as local scenarios (IPCC 2013). For the GMSL, a contribution from thermal expansion and cryospheric contributions have been considered. On the other hand, semi-empirical models (SEMs) are projecting the sea level based on the relationships between global mean temperature and the observed GMSL (Vermeer and Rahmstorf 2009; Grinsted et al. 2010) or between the total radiative forcing in the future and the observed GMSL (Jevrejeva et al. 2008, 2009). According to the fifth AR (AR5) of the IPCC, for very high emissions, a global SLR between 0.52 and $0.98 \mathrm{~m}$ may occur by the year 2100 , while even with aggressive emission reduction, a rise between 0.28 and $0.61 \mathrm{~m}$ may occur.

Regional variation is expected to be the dominating factor over natural variability in sea level change by the end of the 21st century (IPCC 2013). Melting of land ice mass will be the main contributing factor. Some of the regions are expected to experience changes in sea level extensively different from the global mean SLR as revealed from the ensemble mean regional RSL change between 1986-2005 and 2081-2100 under the RCP scenario of 4.5 (IPCC 2013). In the AR5 of IPCC, projections of SLR for nine representative coastal regions including the BOB have been given for all emission scenarios (IPCC 2013). The IPCC for the BOB predicts a SLR between 0.2 and $1 \mathrm{~m}$ for low to high emission scenarios in 2100. The AR5 notes that a collapse of the marine-based sectors of the Antarctic ice sheet if initiated, could potentially add up to further several tenths of a metre of SLR, independent of the scenario that this could be around $0.5 \mathrm{~m}$. This additional amount, when combined with the upper limit of the AR5 highestemission-scenario (RCP8.5) likely range, gives a value of SLR by 2100 of around $1.5 \mathrm{~m}$, not including potential local variations or subsidence. Another recent work (Jevrejeva et al. 2014) estimates $1.8 \mathrm{~m}$ as the upper limit of the global mean SLR by 2100 .

Considering all these predictions of SLR and the severity and intensities of the storm surges in Bangladesh, it is very important to know the inundation pattern and areas which are in direct threat of flooding by 2100 for storm surges along with the probable SLR. A series of experiments were carried out by means of the open-source Delft3D hydrodynamic model which is a widely used 3D modelling suite to investigate the hydrodynamics, sediment transport, morphology and the water quality of fluvial, estuarine and coastal environments (Hydraulics 2006). The software is used and has proved its efficiency in many places around the world. Delft3D has previously been successfully used in coastal applications (Lesser et al. 2004; Elshorbagy et al. 2006; Tung et al. 2009; Van Holland et al. 2010; Horstman et al. 2013). In this context, an investigation has been carried out to estimate the changes of inundation patterns in Bangladesh for three recent storm surges, namely, Sidr, Aila and Roanu. Based on the above discussion, this study has considered four different SLR scenarios for simulating a coastal model: (i) current sea level, (ii) plus $0.5-\mathrm{m}$ SLR, (iii) plus $1.0-\mathrm{m}$ SLR and (iv) plus 1.5-m SLR. A two-dimensional process-based coastal version of the Delft3D model has been implemented to simulate these tropical cyclones considering the different SLR scenarios (figure 1). Among these SLR scenarios, 0.5-m SLR corresponds to a surface temperature increase of $1.5^{\circ} \mathrm{C}$. This condition may arise for the high emission scenario (RCP 8.5) by the year 2040 (IPCC 2013). As this scenario is likely to occur in the near future, it is of more importance for this study.

\section{Study area}

Bangladesh is a floodplain delta which lies in the Ganges-Brahmaputra-Meghna (GBM) basin. This country is crisscrossed with rivers and canals. It extends from the north to the south with a gradual 


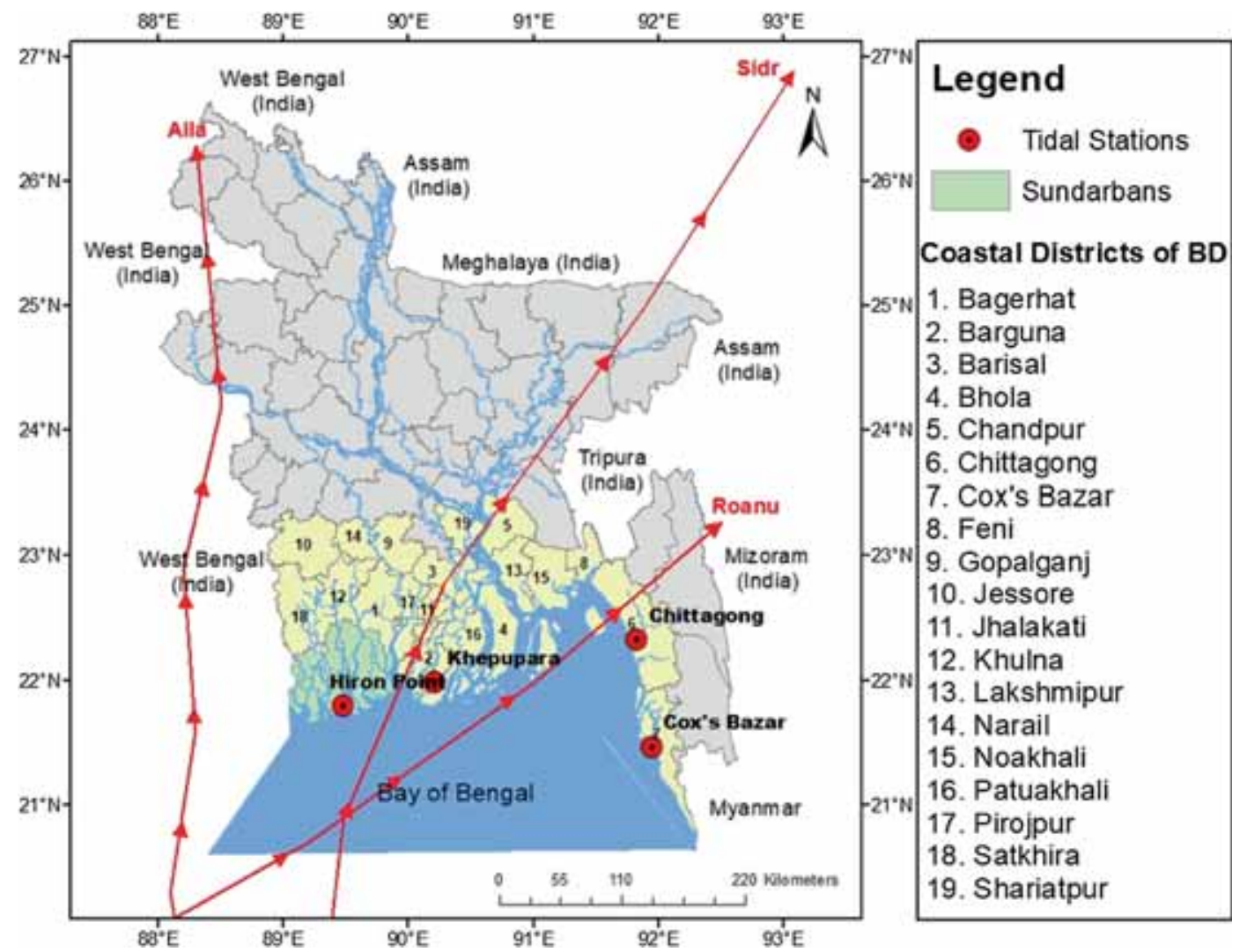

Figure 1. Coastal zone of Bangladesh along with the tidal gauge stations used for calibration.

slope. A coastline of about $710 \mathrm{~km}$ lies in the southern part of the country. The coastal zone of Bangladesh consists of 19 districts covering 147 Upazilas in total (WARPO 2004). Among these 19 districts, 12 districts are directly in touch with the BOB or with an estuary. The coastal zone comprises the $47,201 \mathrm{~km}^{2}$ land area and that is $32 \%$ of the total landmass of Bangladesh (Islam 2004). The major rivers of Bangladesh, GBM and their numerous distributaries discharge into the BOB. This GBM delta and the river network form one of the most productive ecosystems of the world. Most of the coastal zone is flat except for the eastern hilly area which consists of Chittagong and Cox's Bazar regions. In figure 1, the coastal districts of Bangladesh are shown along with the tracks of the cyclones, namely, Sidr, Aila and Roanu.

Among the total population of Bangladesh, nearly $25 \%$ live in the coastal zone which comprises about 38.51 million people (BBS 2011). There are inner and exposed coastal regions which vary very much in population density. The population density in the inner coast is 482 per $\mathrm{km}^{2}$, whereas its value in the exposed coast is 1012 per $\mathrm{km}^{2}$ which is even greater than the country's population density $\left(839\right.$ per $\mathrm{km}^{2}$ ). A study (Islam 2004) shows that there are about 6.8 million households in this zone, most of which are very poor. These people mainly live on fishing, agriculture, shrimp and salt farming. The Sundarbans is the largest mangrove forest in the world and it plays a very important role in maintaining the ecological balance of the southwestern coastal environment. It is also the major source of livelihood of almost 10 million people (Islam 2004).

\section{Methodology}

\subsection{Two-dimensional coastal modelling using Delft3D}

Delft3D model is used for all simulations. Specifically, the Delft3D-FLOW module has been used extensively. Delft Dashboard has also been used to process the cyclone data to prepare the input file for the simulation. Delft3D-FLOW is a widely used multi-dimensional (2D or 3D) hydrodynamic model. It solves the Navier-Stokes equations for an incompressible fluid and follows the Boussinesq approximation. It follows the finite difference method to solve the partial differential 
equations. The time step is selected as $1 \mathrm{~min}$ and horizontal background eddy viscosity and diffusivity are set as $1 \mathrm{~m}^{2} / \mathrm{s}$.

\subsection{Grid and bathymetry}

Many different data sets were merged to create the bathymetry for the model domain. The publicly available general bathymetric chart of the oceans (GEBCO) and ETOPO data are very coarse ones which are applicable to deeper water but fail to accurately represent the bathymetry of shallow water and inland areas. However, for this research, these shallow water and inland areas are of great importance. That is why the existing bathymetry data have been refined using the data from the Bangladesh Water Development Board (BWDB). The Institute of Water and Flood Management (IWFM) also conducted a bathymetric survey under the ESPA Deltas Project which has been incorporated in the existing bathymetry. Moreover, the tidal charts of Bangladesh Navy in the shallow region have been collected as hard copies and digitised afterwards. In order to have the accurate scenario in the inland areas due to the storm surges, the polder elevation data of the 139 coastal polders have also been incorporated in the updated bathymetry. Finally, this updated bathymetry is used for the simulations performed for storm surges. This bathymetry data is currently in the WGS84 coordinate system and the vertical data in the MSL. The very good performance of this bathymetry for hydrodynamic modelling has been proved in the studies of Tazkia et al. (2017) and Krien et al. (2016, 2017). The coastline has been digitised using high-resolution $(30 \mathrm{~m})$ freely available Landsat 8 images. Table 1 shows the datasets which have been merged to develop the updated bathymetry.
This model has been developed using a structured mesh. Delft3D has options for both structured and unstructured meshes but the unstructured version is not open source yet. Initially, within the domain, a rectangular mesh is created using the Delft Dashboard. This mesh has a resolution of $0.006^{\circ}$ which is about $666 \mathrm{~m}$ in length. It expands in both $\mathrm{M}$ and $\mathrm{N}$ directions. This mesh is later edited using the Delft3D-RFGRID tool to refine and orthogonalise for better outcome. The Delft3D-QUICKIN tool is used to interpolate the bathymetry data and create a depth file which later is used as an input file for the model. For this simulation, the Manning's coefficient $(n)$ is set as 0.02 throughout the whole area. In figure 2 , the model domain and updated bathymetry along with the rectangular mesh used are shown.

\subsection{Open boundary and cyclonic forcing}

Open boundary conditions are used in this model. In the $\mathrm{BOB}$, time series data of the water level have been prescribed along the open boundary. These water level data have been generated using the TPXO 7.2 global inverse tidal model. This model provided the time series of water level for different tidal components. Daily discharge data have been provided in three different locations as the upstream boundaries. The Hardinge bridge in the Ganges river, the Bahadurabad transit in the Brahmaputra river and the Bhairab Bazar railway crossing in the Meghna river are the locations where upstream boundaries are imposed. These upstream boundaries are imposed to simulate the effects of freshwater from the major rivers in the GBM delta. The tide generated by the TPXO 7.2 global inverse tidal model has been validated by Tazkia et al. (2017).

Table 1. Description of the datasets incorporated in the bathymetry.

\begin{tabular}{|c|c|c|c|}
\hline Data & Source & Extent & Resolution \\
\hline GEBCO & GEBCO (2014) & Global grid & $30 \operatorname{arcs}$ \\
\hline $\begin{array}{l}\text { Digital elevation model } \\
\text { (DEM) }\end{array}$ & FAP 19 & Coastal areas & $300 \mathrm{~m} \times 300 \mathrm{~m}$ \\
\hline River bathymetry survey & BWDB & Rivers of coastal areas & $\begin{array}{l}\text { Cross-section along the rivers } \\
\text { (variable) }\end{array}$ \\
\hline River bathymetry survey & ESPA Delta Project of IWFM & Rivers of coastal areas & $\begin{array}{l}\text { Cross-section along the rivers } \\
\text { (variable) }\end{array}$ \\
\hline $\begin{array}{l}\text { Coastal polders boundary } \\
\text { and elevation }\end{array}$ & CEIP-1 project of BWDB & Coastal areas & Along the polder dikes (variable) \\
\hline Coastlines of Bangladesh & Landsat 8 & Coastal areas & $30 \mathrm{~m}$ \\
\hline
\end{tabular}




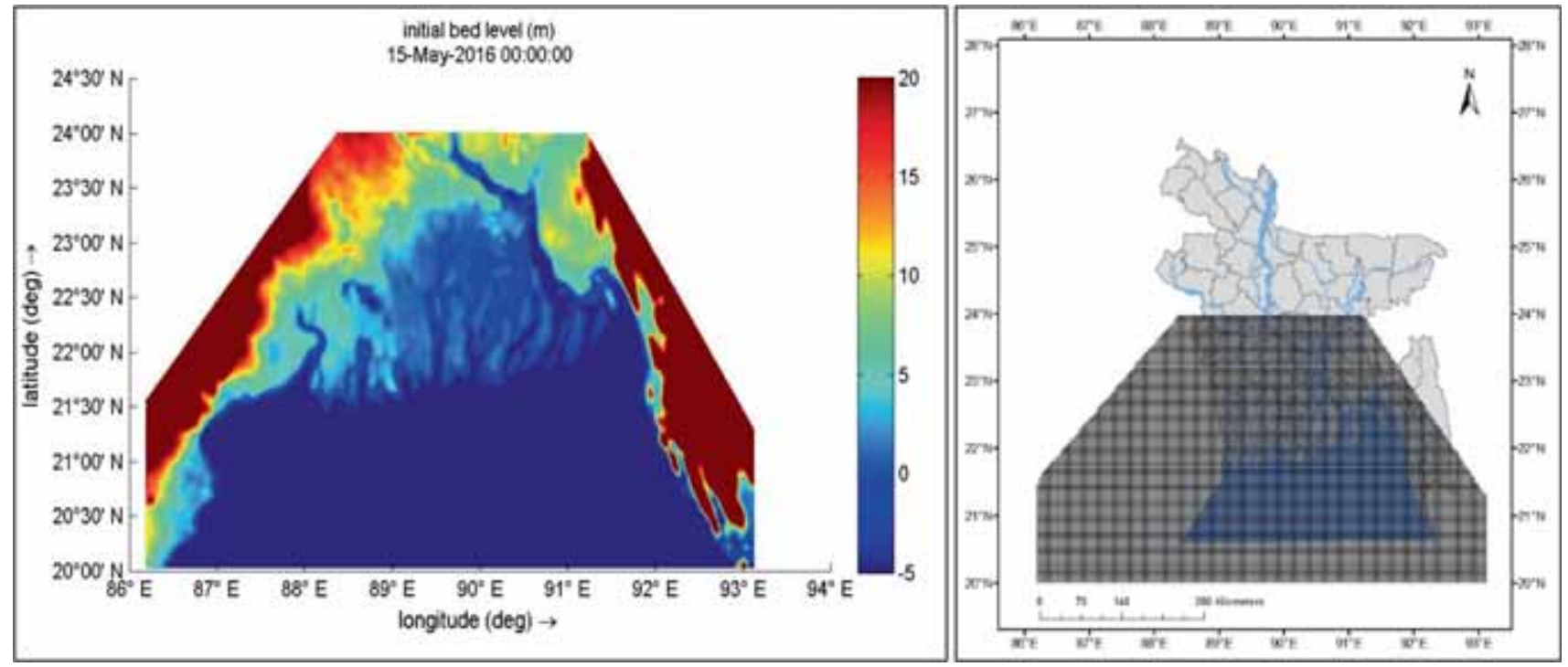

Figure 2. Model domain and structured mesh.
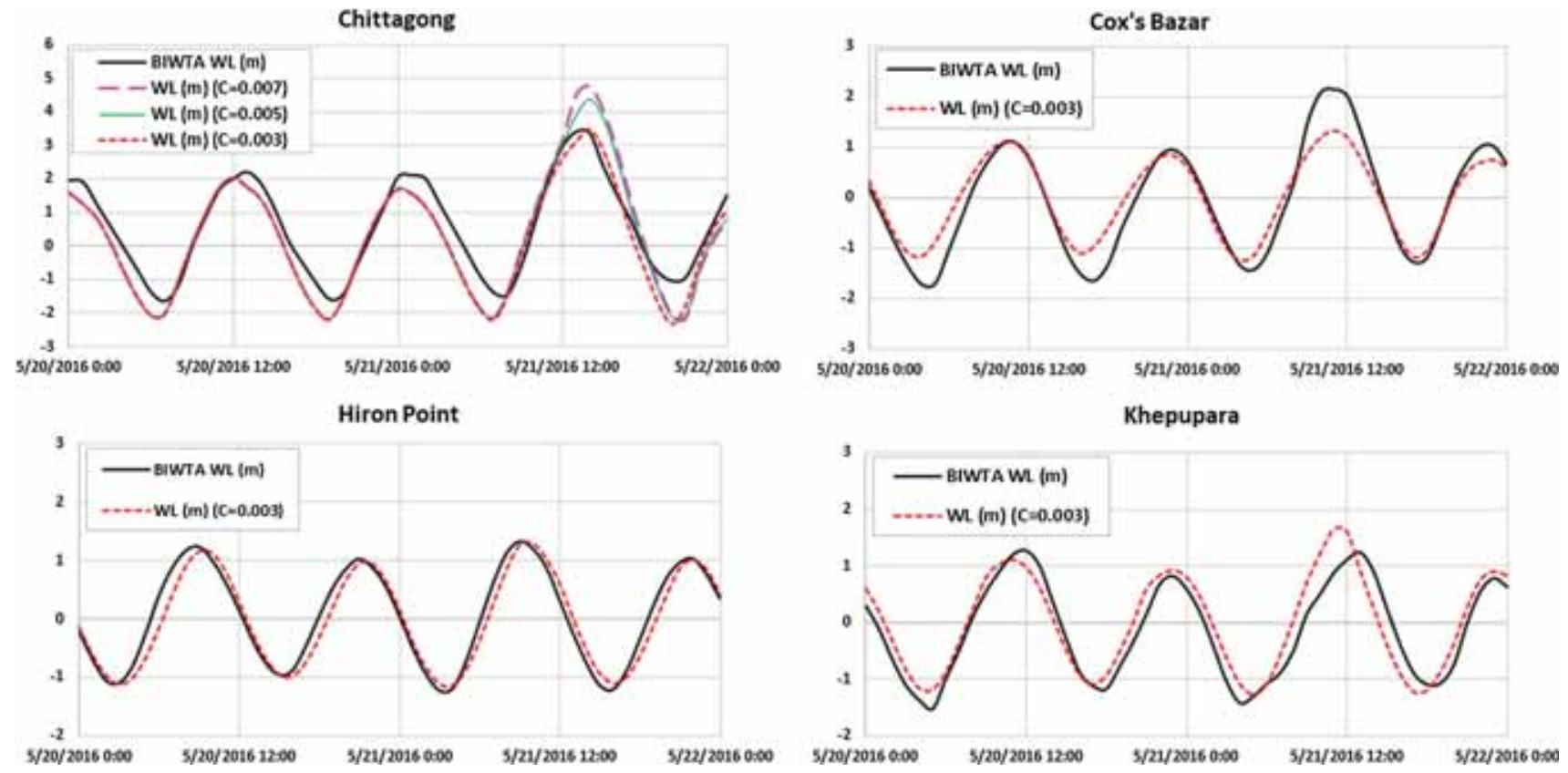

Figure 3. Calibration and validation of the model.

The tropical cyclone toolbar of the Delft3D dashboard has been applied to generate winds and pressure in the modelling domain for the three recent cyclones, namely, Sidr, Aila and Roanu.

\section{Results and discussion}

\subsection{Validation of the Delft3d model for storm surges}

The model is calibrated for different drag coefficients between the wind and sea surfaces. The default value assigned to Delft3D is 0.007. But this value of drag coefficient indicates the maximum water level at Chittagong (figure 3) as higher than the observed value. Therefore, the model is run for various drag coefficient values $0.007,0.005$ and 0.003 . Finally, 0.003 of the drag coefficient value has been accepted for further work. With a 0.003 drag coefficient, the water level is validated at Hiron Point, Cox's Bazar and Khepupara (figure 3). The coefficient of the determination of the model output at Hiron Point, Cox's Bazar and Khepupara is $0.92,0.92$ and 0.88 , respectively. 

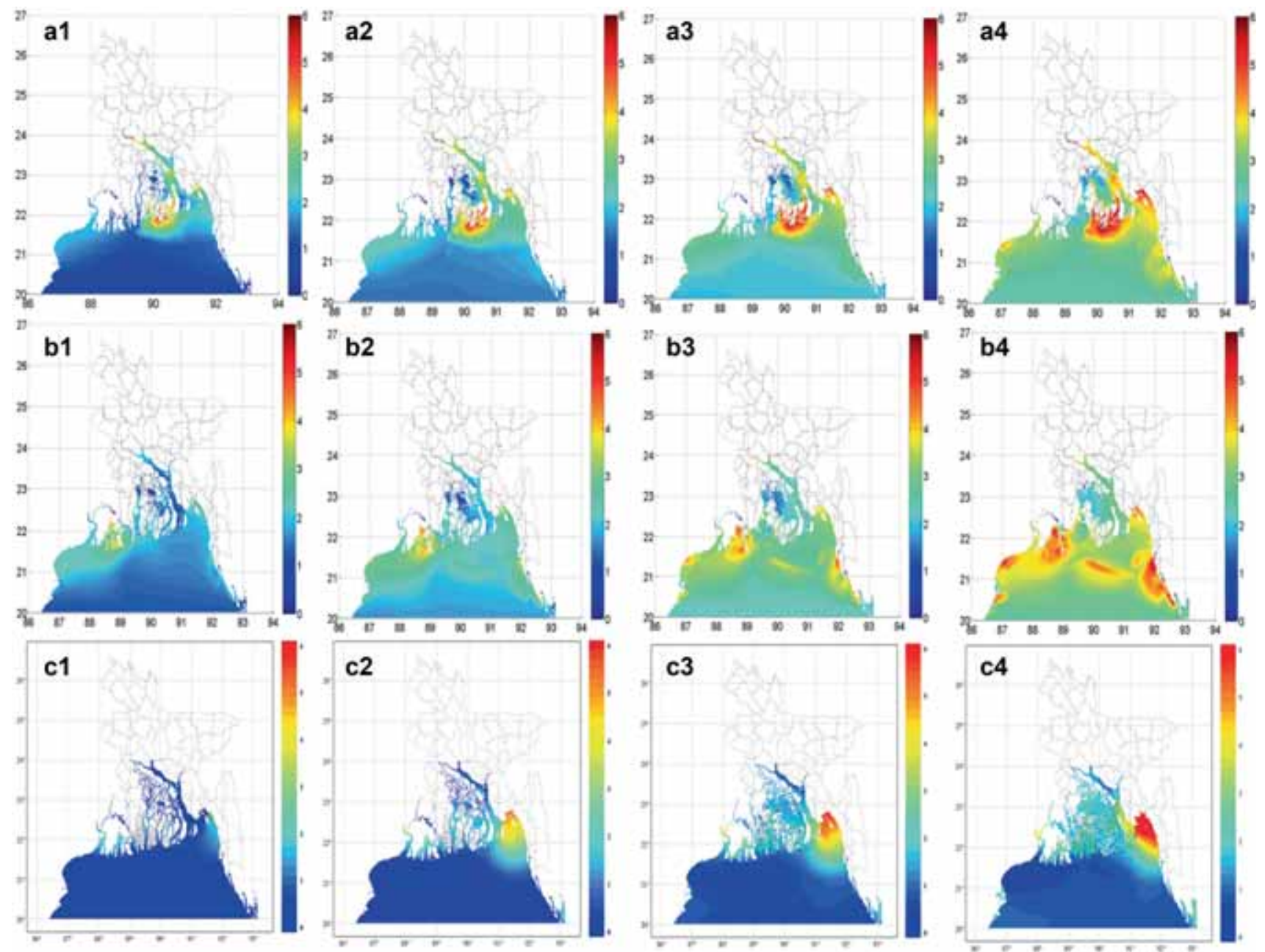

Figure 4. Maximum water level for cyclones under different SLR conditions. Suffix (a) for Sidr, (b) for Aila and (c) for Roanu. Suffix 1 for cyclone with the current sea level, 2 for cyclone plus $0.5-\mathrm{m}$ SLR, 3 for cyclone plus 1.0-m SLR and 4 for cyclone plus 1.5-m SLR.

\subsection{Inundation analysis}

Figure 4 shows the inundation pattern for cyclones Sidr, Aila and Roanu. It is clear that for cyclone Sidr, with the current sea level (figure 4a1), inundation occurs avoiding the polder-protected areas. If $0.5-\mathrm{m}$ SLR is added with the surge of cyclone Sidr (figure 4a2), the polders are still fully able to protect the areas from inundation. Even with 1-m (figure 4a3) and 1.5-m (figure 4a4) SLR, the surge of cyclone Sidr cannot overflow the polders at most of the places. It can also be seen from figure 4(b1-b4) that although the tracks of Sidr and Aila are completely different, the inundation pattern is similar. Within Bangladesh territory, the inundation pattern is governed by the map of existing polders. For Roanu, the track is different and the inundation pattern is also different from that of Sidr and Aila. For cyclone Roanu, with the current sea level (figure 4c1) and with $0.5-\mathrm{m}$ SLR (figure 4c2), the inundation is less than that of Sidr and Aila. But for 1-m (figure 4c3) and 1.5-m (figure 4c4) SLR, the inundation surpasses that of the other cyclones.

Table 2 shows the statistics of the inundation areas and the affected population for cyclones Sidr, Aila and Roanu along with probable SLRs. The total inundated area excluding permanent water body for cyclone Sidr with the current sea level is approximately $1484 \mathrm{~km}^{2}$ which is nearly $1.14 \%$ of the total area of Bangladesh. If $0.5-\mathrm{m}$ SLR is added to cyclone Sidr, the total inundated area excluding permanent water bodies becomes $3380 \mathrm{~km}^{2}$ which is nearly $2.6 \%$ of the total area of Bangladesh. It means a 0.5-m SLR addition causes nearly double the inundated areas compared to the present condition. The total inundated area excluding permanent water bodies for only 

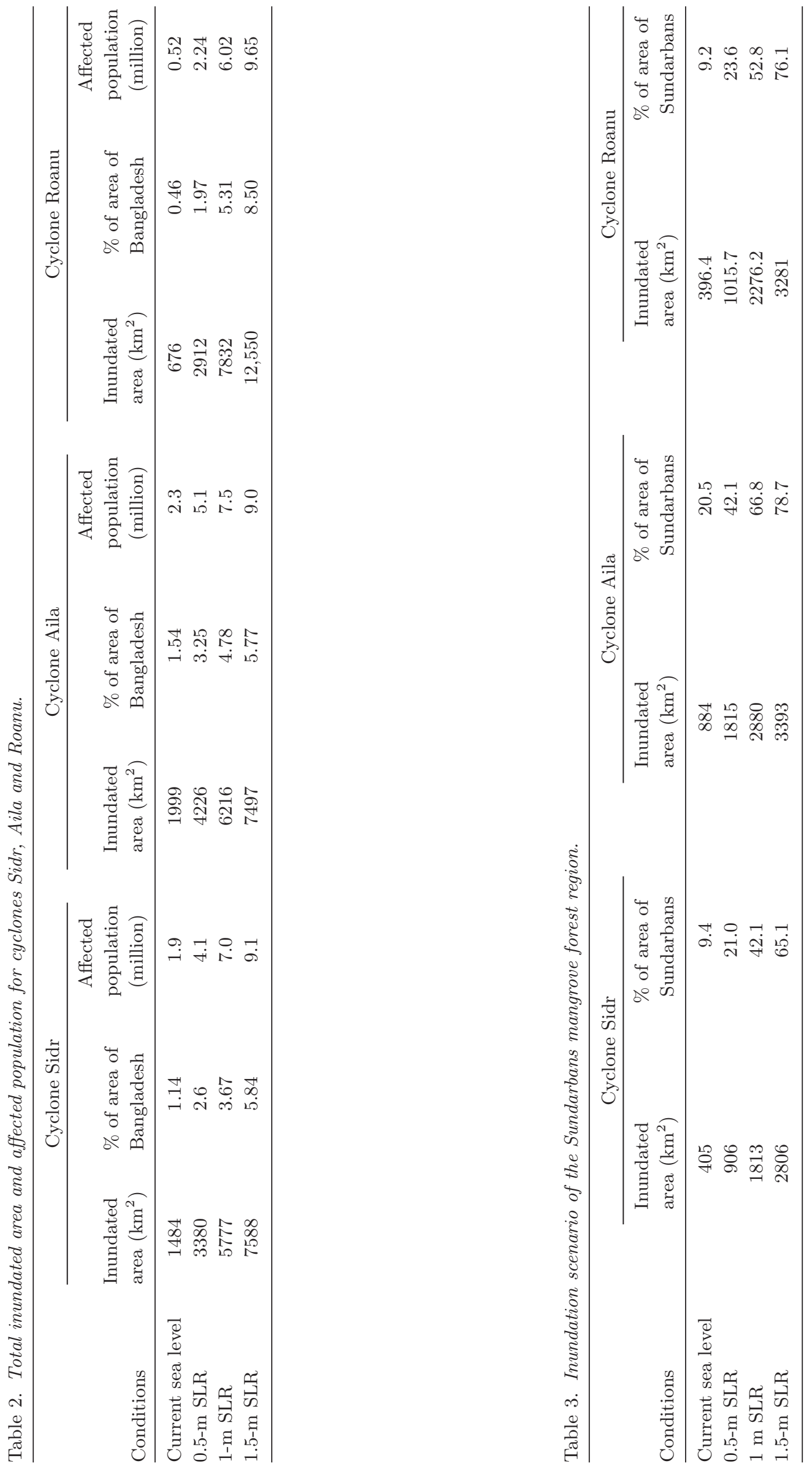
1.0-m SLR is found to be approximately $5777 \mathrm{~km}^{2}$ which is nearly $7 \%$ of the total area of Bangladesh. Therefore, including cyclone Sidr with a 1.5-m SLR causes about three times increase in the inundated area compared to the same cyclone with the current sea level. Cyclone as strong as Sidr along with the $1.5-\mathrm{m}$ SLR will inundate $7588 \mathrm{~km}^{2}$ which is about $5.84 \%$ of the total area of Bangladesh. Cyclone Aila has nearly similar impacts but the scenario for Roanu is much worse. The statistics for all these cyclones are shown in table 2 .

The inundation statistics of the Sundarbans are shown in table 3 . The cyclone Sidr with the current sea level inundates nearly $9.4 \%$ of the Sundarbans, whereas introducing $0.5,1$ and $1.5 \mathrm{~m}$ of SLR with Sidr inundates $21 \%, 42.1 \%$ and $65.1 \%$ of the Sundarbans, respectively. Cyclone Aila along with the SLR is more devastating than Sidr with SLR in terms of inundation for Sundarbans because of its track and time of landfall at the Bangladesh coast. Cyclone Roanu along with the SLR causes similar inundation as Aila.

This study has considered SLR projections based on the IPCC reports which count changes of thermal expansion, glaciers and ice sheet melting. However, uncertainty exists on the climate model for capturing bio-physical processes as well as the socio-economic drivers of climate change. The model also uses a number of gridded data and satellite-driven geospatial data which would suffer from inaccuracy. This study also did not consider relative SLR which includes the changes of sea level related to the earth by including various land processes such as sedimentation, tectonic uplift, coastal subsidence, etc. Hence, the possible changes of storm surge inundation patterns in coastal Bangladesh generated in this study also contain uncertainties that should be taken into account before the application of these results.

\section{Conclusion}

This paper presented the possible changes of storm surge inundation patterns of the coastal areas of the GBM delta considering the high-end climate emission scenarios. This study investigated the ability of an open source coastal model, Delft3d, using improved bathymetric and topographic data, to predict the possible changes of the water levels and coastal inundation patterns in the northern BOB. We have applied three possible scenarios of
SLR by considering the 'business-as-usual' climate change scenario RCP 8.5. The lower boundary and upper boundary of the projected SLR of RCP 8.5 scenario of a value of 0.5 and $1 \mathrm{~m}$ as well as an extreme case considering the subsidence and a rapid collapse of the Antarctic ice sheet with a value of $1.5 \mathrm{~m}$ have been chosen to simulate the surge-induced inundations.

It has been found that the inundation areas of these cyclones will be increased for each of the possible SLR scenarios. For the category 4 cyclone Sidr, the inundation areas will be increasing from $405 \mathrm{~km}^{2}(1.1 \%)$ to $906 \mathrm{~km}^{2}$ (2.6\%), $1813 \mathrm{~km}^{2}$ $(3.7 \%)$ and $2806 \mathrm{~km}^{2}(5.8 \%)$ for a SLR of 0.5 , 1 and $1.5 \mathrm{~m}$, respectively. This would affect the population from 1.9 million to 4.1 million, 7.0 million and 9.1 million for a SLR of 0.5, 1 and $1.5 \mathrm{~m}$, respectively. Moreover, the world's largest mangrove forest, the Sundarbans would face an additional inundation area of 9.4-21.0\%, $42.1 \%$ and $65.1 \%$ for the above three SLR scenarios. For cyclones Aila and Roanu, we conclude with a similar pattern of increasing inundation in the GBM delta as well as over the unprotected mangrove forest, the Sundarbans. The greatest inundation in the Sundarbans from storm surges would be observed for the cyclone Aila which is probably $78.7 \%$ of the forest area. As cyclone Aila passed close to the Sundarbans, a similar event will greatly affect that region under the SLR scenarios. On the other hand, the maximum affected population would be about 9.6 million for cyclone Roanu under a 1.5-m SLR scenario. Cyclone Roanu will be more devastating in the future under the high SLR scenario as it passed through the densely-populated Chittagong region which is considered as the business capital of Bangladesh.

The modelled scenarios depicted in this study can only illustrate some plausible futures for the increasing coastal inundation patterns for different sea-level rise conditions. However, it is not possible to give the exact estimation of the probabilities of different levels of risks associated with storm surges. Moreover, we have forced the model with only the SLR scenarios without accounting for the possible changes of the morphological conditions or the local variations of the sea-level height of the complex shorelines of the GBM delta.

Despite the limitations of this study, the possible changes of the inundation presented by the model scenarios for the various categories of storm surges will provide an idea about the possible changes in risks in the future. With our conclusions in mind, 
it is also worthy of mention that the ecology and biodiversity of the Sundarbans will face devastating effects of storm surges in the future, as the sea level will undoubtedly continue to rise.

\section{Acknowledgements}

The research leading to these results has received funding from the European Union Seventh Frame work Programme FP7/2007 -2013 under Grant Agreement No. 603864 (HELIX: High-End cLimate Impacts and eXtremes; http://www.helixclimate. eu). We acknowledge financial support from CNES (through the TOSCA projects BANDINO and SeaLevelAlk) for purchasing and collecting tidal data. We are thankful to Indo-French Cell for Water Sciences (Indian Institute of Science, Bangalore, India) for hosting SR, PS, ART, YK, FD and LT for project meetings during this study.

\section{References}

Alam M S and Jabed M A 2015 Cyclones and causes of cyclones over the south west coastal area of Bangladesh; Banglavision 15(1) 91-104.

Bangladesh Bureau of Statistics (BBS) 2011 Population and housing census 2011.

Church J A and White N J 2011 Sea-level rise from the late 19 th to the early 21st century; Surv. Geophys. 32(4-5) 585-602.

Dastagir M R 2015 Modeling recent climate change induced extreme events in Bangladesh: A review; Weather Clim. Extremes 7 49-60.

Elshorbagy W, Azam M H and Taguchi K 2006 Hydrodynamic characterization and modeling of the Arabian Gulf; J. Waterw. Port C.-ASCE 132(1) 47-56.

Ericson J P, Vörösmarty C J, Dingman S L, Ward L G and Meybeck M 2006 Effective sea-level rise and deltas: Causes of change and human dimension implications; Glob. Planet. Change. 50(1-2) 63-82.

Grinsted A, Moore J C and Jevrejeva S 2010 Reconstructing sea level from paleo and projected temperatures 2000 to 2100 AD; Clim. Dyn. 34 461-472.

Han W, Meehl G A, Rajagopalan B, Fasullo J T, Hu A, Lin J and Wallcraft A et al. 2010 Patterns of Indian Ocean sea-level change in a warming climate; Nat. Geosci. 3(8) 546 .

Horstman E, Dohmen-Janssen C M and Hulscher S J 2013 Modeling tidal dynamics in a mangrove creek catchment in Delft3D; In: Coastal dynamics 2013, EPOC, Arcachon, France, June 2013, pp. 24-28.

Hydraulics D 2006 Delft3D-FLOW, simulation of multidimensional hydrodynamic flows and transport phenomena, including sediments; User manual, Delft, Holanda.

IPCC 2013 Climate change 2013: The physical science basis. Contribution of working group I to the fifth assessment report of the intergovernmental panel on climate change (eds) Stocker T F, Qin D, Plattner G-K, Tignor M, Allen S K, Boschung J, Nauels A, Xia Y, Bex V and Midgley P M, Cambridge University Press, Cambridge, UK and New York, NY, USA, p. 1535.

Islam M R 2004 Where land meets the sea: A profile of coastal zone of Bangladesh; The University Press Ltd., Dhaka, 317p.

Jevrejeva S, Moore J C and Grinsted A 2008 Relative importance of mass and volume changes to global sea level rise; J. Geophys. Res. 113 D08105.

Jevrejeva S, Grinsted A and Moore J C 2009 Anthropogenic forcing dominates sea level rise since 1850; Geophys. Res. Lett. 36 L20706.

Jevrejeva S, Grinsted A and Moore J C 2014 Upper limit for sea level projections by 2100; Environ. Res. Lett. 9(10) 104008.

Kreft S and Eckstein D 2013 Who suffers most from extreme weather events?; Global Climate Risk Index 2014, Germanwatch.

Krien Y, Mayet C, Testut L, Durand F, Tazkia A R, Islam A K M S, Gopalakrishna V V, Becker M, Calmant S, Shum C K and Khan Z H 2016 Improved bathymetric dataset and tidal model for the Northern Bay of Bengal. Mar. Geodesy 39(6), 422-438.

Krien Y, Testut L, Islam A K M S, Bertin X, Durand F, Mayet C and Ballu V et al. 2017 Towards improved storm surge models in the northern Bay of Bengal; Cont. Shelf. Res. 135 58-73.

Lesser G R, Roelvink J A, Van Kester J A T M and Stelling G S 2004 Development and validation of a threedimensional morphological model; Coast. Eng. 51(8) 883-915.

Moss R, Babiker W, Brinkman S, Calvo E, Carter T, Edmonds J and Jones R N 2008 Towards new scenarios for the analysis of emissions: Climate change, impacts and response strategies; IPCC Expert Meeting Report.

Moss R H, Edmonds J A, Hibbard K A, Manning M R, Rose S K, Van Vuuren D P and Meehl G A et al. 2010 The next generation of scenarios for climate change research and assessment; Nature 463(7282) 747.

Ramamasy S and Baas S 2007 Climate variability and change: Adaptation to drought in Bangladesh; A resource book and training guide, FAO, United Nations, Rome.

Shrestha M L, Ferdousi N and Uddin S 1998 The impact of tropical cyclones on the coastal regions of $S A A R C$ countries and their influence in the region; SAARC Meteorological Research Centre, Agargaon, Bangladesh.

SMRC 2003 The vulnerability assessment of the SAARC coastal region due to sea level rise: Bangladesh case, SMRC publication No. 3; SAARC Meteorological Research Centre, Dhaka.

Tazkia A R, Krien Y, Durand F, Islam A S, Testut L, Papa F and Bertin X 2017 Seasonal modulation of M2 tide in the northern Bay of Bengal; Cont. Shelf Res. 137 154-162.

Tung T T, Walstra D J R, van de Graaff J and Stive M J 2009 Morphological modeling of tidal inlet migration and closure; J. Coast. Res. 56 1080-1084.

Unnikrishnan A S and Shankar D 2007 Are sea-level-rise trends along the coasts of the north Indian Ocean consistent with global estimates?; Glob. Planet. Change 57(3) 301-307. 
Van Holland G, Verheyen B, Jacobs S, Vandenbruwaene W, Temmerman S, Meire P and De Schutter J 2010 Simulation of hydrodynamics and transport of fine sediments in vegetated polders with a controlled reduced tide: Pilot project Lippenbroek; In: Proceedings of the 8th International Symposium on ecohydraulics 2010 (ISE 2010): Bridging between ecology and hydraulics and leading the society's new need - living with nature, September 2010, Seoul, South Korea, pp. 1775-1782.

Vermeer M and Rahmstorf S 2009 Global sea level linked to global temperature; Proc. Nat. Acad. Sci. USA 106(51) 21527-21532.

Warrick R A and Oerlemans J 1990 Climate change - The IPCC scientific assessment; pp. 257-281.

Corresponding editor: KAVIRAJAN RAJENDRAN
Water Resource Planning Organization (WARPO) 2004 Whereland meets the sea - A profile of the coastal zone of Bangladesh; Dhaka University Press Limited, Dhaka, Bangladesh.

Williams S J, Gutierrez B T, Titus J G, Gill S K, Cahoon D R, Thieler E R, Anderson K E, FitzGerald D, Burkett $\mathrm{V}$ and Samenow J 2009 Sea-level rise and its effects on the coast; In: Coastal sensitivity to sea-level rise: A focus on the mid-Atlantic region. A report by the U.S. climate change science program and the subcommittee on global change research (eds) J G Titus, K E Anderson, D R Cahoon, D B Gesch, S K Gill, B T Gutierrez, E R Thieler and S J Williams, U.S. Environmental Protection Agency, Washington DC, pp. 11-24. 